\title{
Looking Forward to Beijing Agricultural Informationization in the 13th five years plan
}

\author{
Qing-feng WEI ${ }^{\star 1,2, a}$ Yan TANG ${ }^{3, b}$ Chang-shou LUO ${ }^{1,2, c}$ \\ ${ }^{1}$ Institute of Information on Science and Technology of Agriculture, Beijing Academy of Agriculture \\ and Forestry Sciences,Beijing,China \\ ${ }^{2}$ Beijing Research Center of Engineering Technology on Rural Distance Information Service, \\ Beijing,China \\ ${ }^{3}$ Rural Development center of Beijing Municipal Science and Technology Commission , \\ Beijing,China

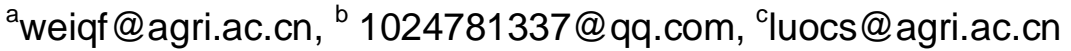

\begin{abstract}
Keywords: Beijing, Rural area, Agricultural Informationization
Abstract. By the sample survey and site visit, and the data from the National Statistics Bureau and the Beijing Statistics Bureau, development status of rural informationization in Beijing was investigated. The results showed that there was important progress on infrastructure construction, farmers' information ability, agricultural information system development and application, and agricultural information service system construction. On the new stage of the 13th five years plan, it needs pay attention to concept guidance and information skill training to cultural new capital modern peasants, construction multi channel to provide accurate information service for farmers, perfect mechanism and hotspot tracking to support the industry, and finally promote the development of agriculture modernization in Beijing city.
\end{abstract}

\section{Introduction}

Agriculture informationization is an important way to realize agriculture modernization. After continuing hard work in the period of the 11th and 12th five years plan, agricultural informationization develops rapidly, and makes a great contribution for rural income promotion and urban-rural areas integration. In this study, based on the investigation data, analyses the status and problem, and offer some proposal for its development in the 13th five years plan. It has great significance of providing some new ideas for the new stage, and will be also better to Beijing to play the leading role in the construction of agriculture informationization.

\section{Materials and methods}

Take 18 enterprises and institutions which service for agriculture as samples to investigation by questionnaire, and visit 13 countryside to gain the first hand data and information. According to the result, statistic and analyze the status on information infrastructure, information ability, application of agricultural information, service system.

\section{The status of Beijing agriculture informationization}

\section{Information infrastructure}

Comparative analysis of rural-urban household access rate of information transmission network. The household access rate of information transmission network is a reflection of the actual utilization of communication networks. According to Fig. 1 above, the urban and rural access rates of mobile communication networks, and broadcasting networks were essentially flat. The broadcasting network is the highest, up to $100 \%$. Followed by mobile communication network, up to $99.5 \%$. Farmers are very familiar with radio and television, so, it makes a higher rate of use. For the widely use of mobile phone, the mobile communication network in rural areas is also higher. 


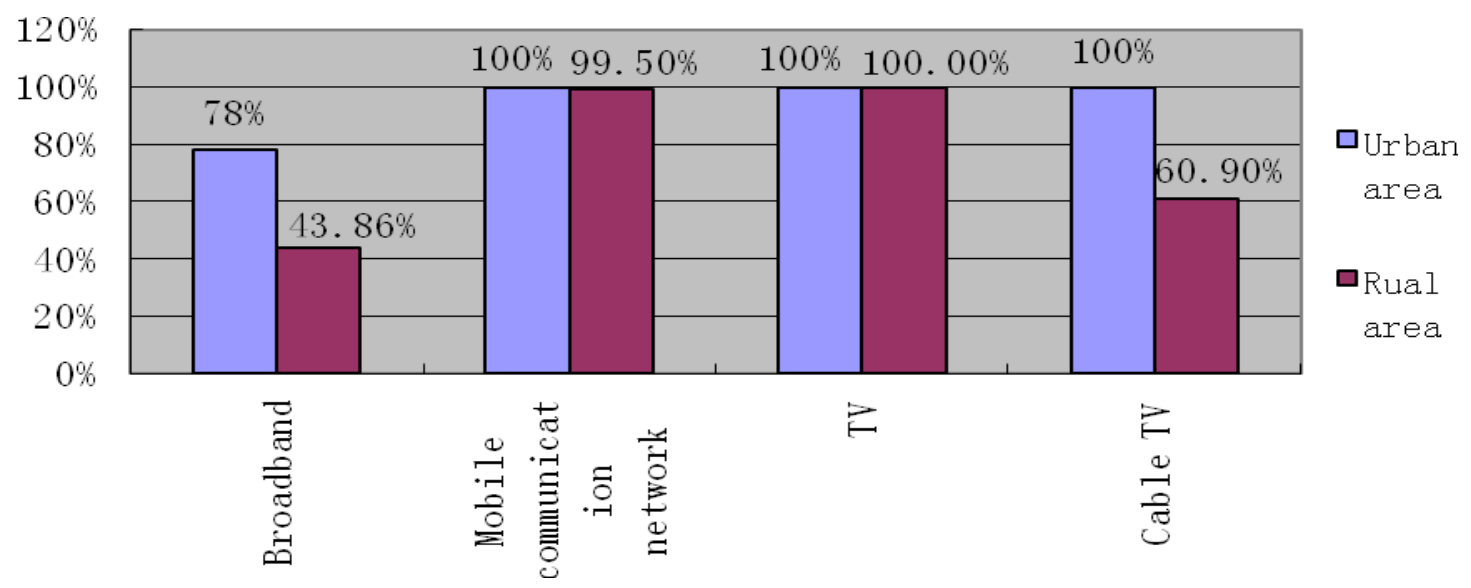

Fig. 1 Rural-urban household access rate of information transmission network

Comparative analysis of rural-urban household ownership rate of information equipment. Information equipment is the important carrier of information. From the Fig. 2 above, in addition to the computer, the ownership rate gap of additional equipment is smaller. Among them, the mobile phone is $234.9 \%$, it is the highest, $8.9 \%$ above the urban area. It indicates that the mobile phone is the most important communication tool for farmers. The second is the color TV set. It is $130.6 \%$. It indicates that in case of new information media emerging, TV is still an important channel of information. The fixed phone is dropped to $85.6 \%$ for the increasing of mobile phone. Compared with the above information equipment, the computer is relatively low, it is $66.7 \%$.

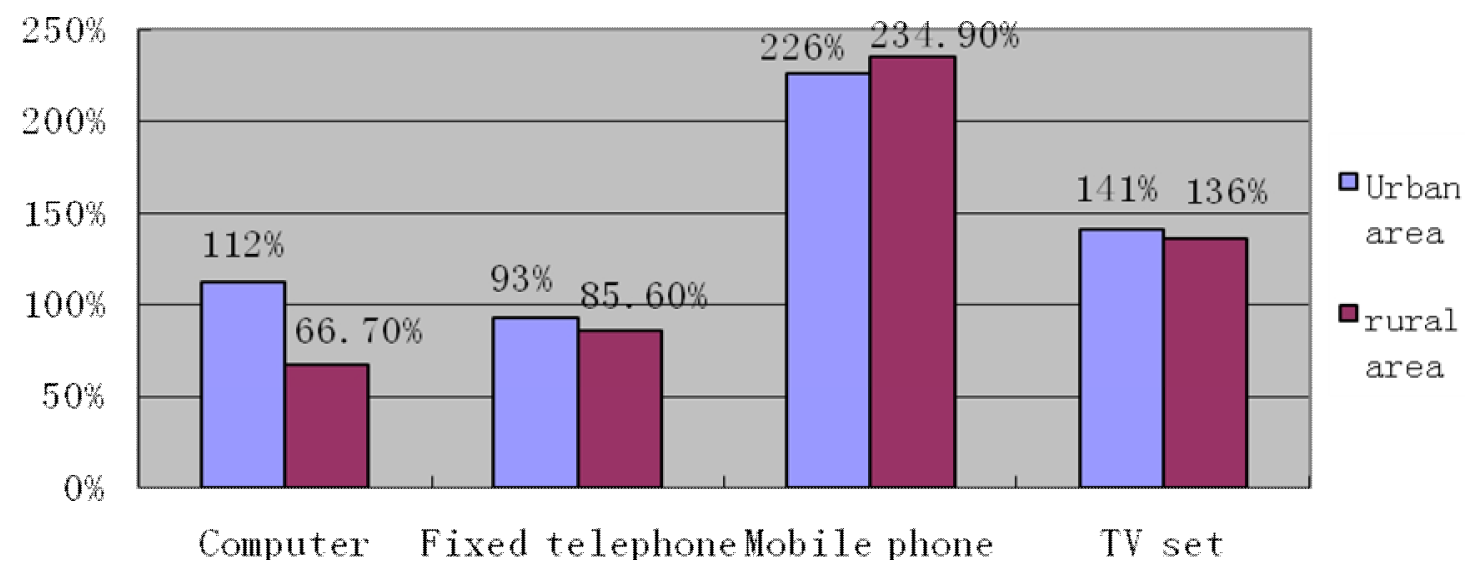

Fig.2 Rural-urban household ownership rate of information equipment

\section{Information demand of farmers}

\section{Farmers' information consciousness}

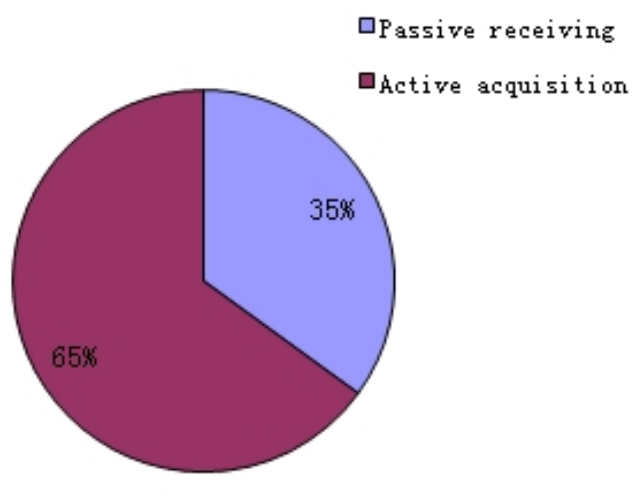

Fig.3 Initiative statistics of farmers' information acquisition

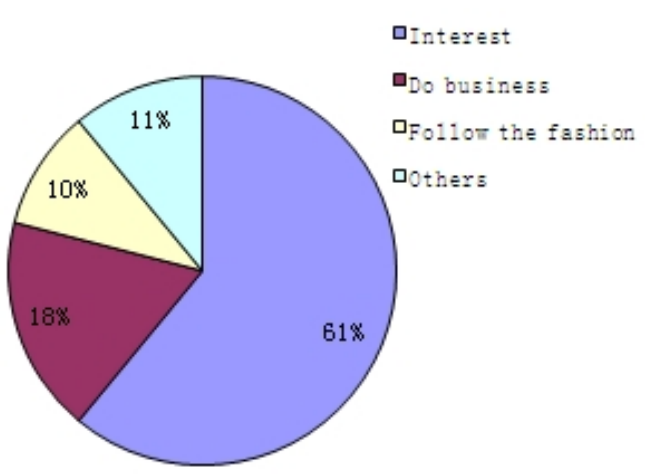

Fig.4 Reasons statistics of farmers' obtaining information initiatively 
From the data above, $65 \%$ of farmers are enthusiastic, only $35 \%$ are passive to accept. Among them, $61 \%$ are for their interest, $18 \%$ think it good to do business, about $21 \%$ follow the trend. It indicates that, along with the development of agricultural informationization, farmers are initiative to know it and applied in practice.

The willingness of information skills training. From the Fig. 6 above, the group which wants to receive the training is $69.5 \%$. So, implementation of serials training activity to promote the information skill has great significance to play the network media value.

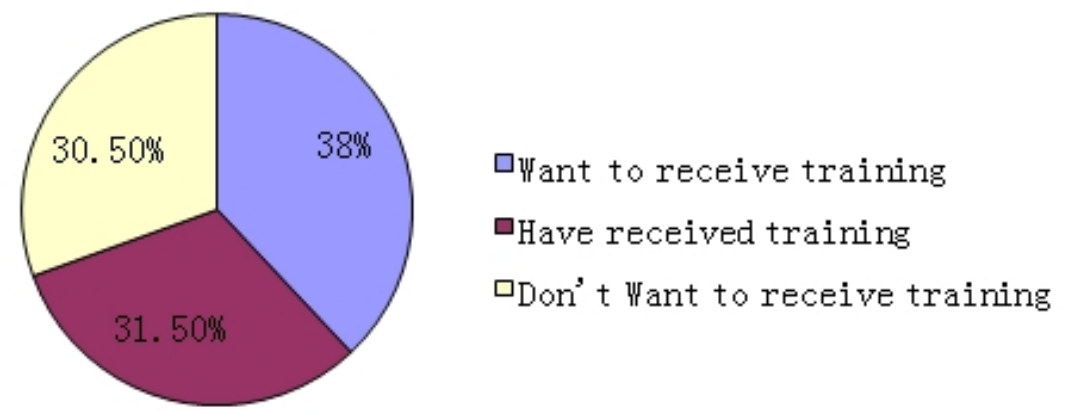

Fig.5 The proportions of information skills training willingness

The application of agricultural information system.

Agricultural production information system. According to the function, classify and statistic the application system, the proportions are as follows:
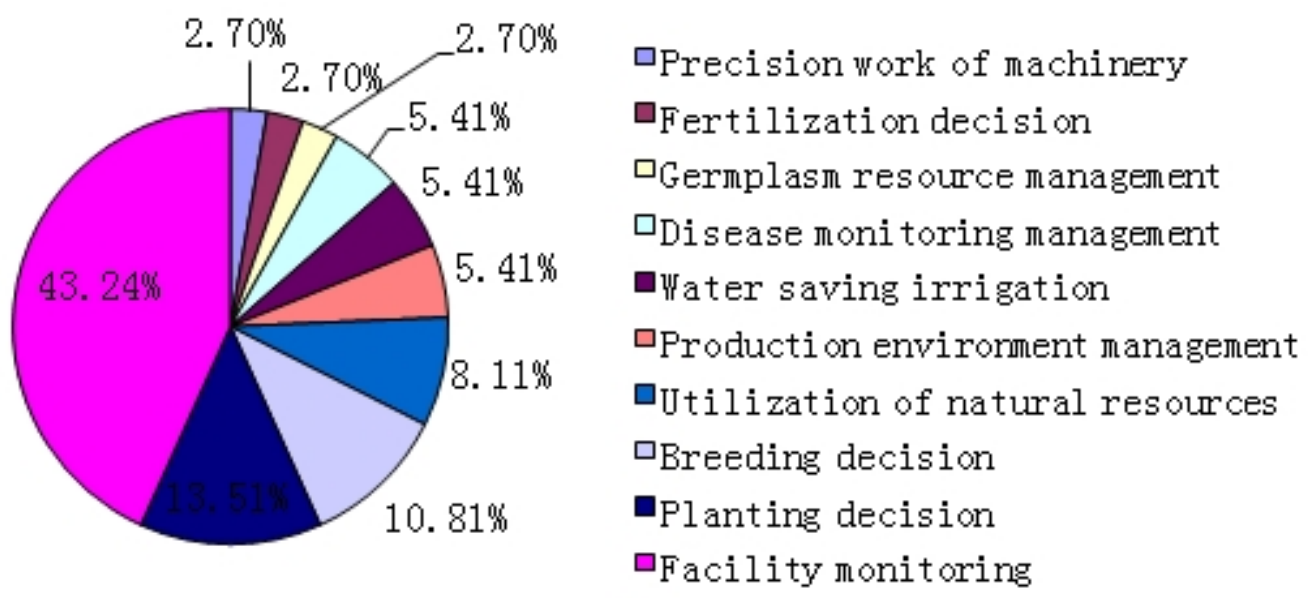

Fig.6 The proportions of agricultural production system

According to the Fig.7, the proportion of all kinds of systems is consistent with the proportion of the agricultural industry structure in Beijing. Facilities monitoring system (mainly the internet of things technology) is accounted for $43.24 \%$. For the dominance of vegetable, as well as the technology advantages of internet of things, it leads to the system of facilities monitoring system has been widely attention and application. Secondly, planting and breeding decisions class system is followed, accounted for $21.62 \%$ and $10.81 \%$ respectively. It indicates that agriculture infomationization provides a support for agro-based industries. In addition, the system is applied on product environmental management, water saving irrigation, the natural resource management (such as water, soil, etc.), germplasm resource management, precision work of agricultural machinery, ect.. Almost cover all aspects of the process of agricultural production.

Agricultural marketing information system. According to the function, classify and statistic the system, the proportions are as follows:

According to the Fig.8, agricultural e-commerce and logistics distribution are the hot spot in agricultural market. Their proportions are $37.5 \%$ and $31.25 \%$ respectively. With the improvement of cold chain logistics technology, agricultural e-commerce applications will have a sustainable development, it will also promote the development of the logistics distribution system in turn. In addition, agricultural business management information system and market monitoring system are 
$18.7 \%$ and $12.5 \%$. Compared with other fields of market informationization, there is further room for improvement.

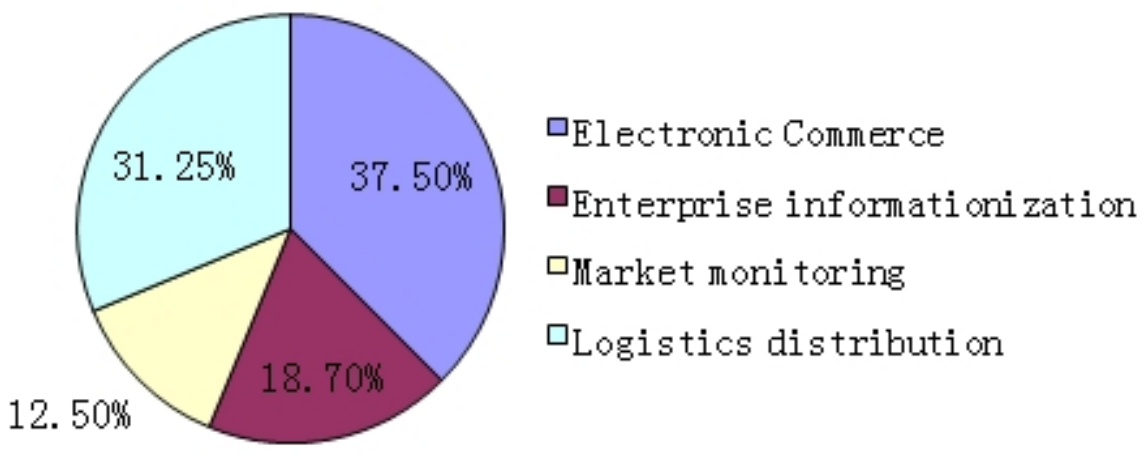

Fig.7 The proportions of agricultural marketing system

Agricultural management information system. According to the function, classify and statistic the system, the proportions are as follows:
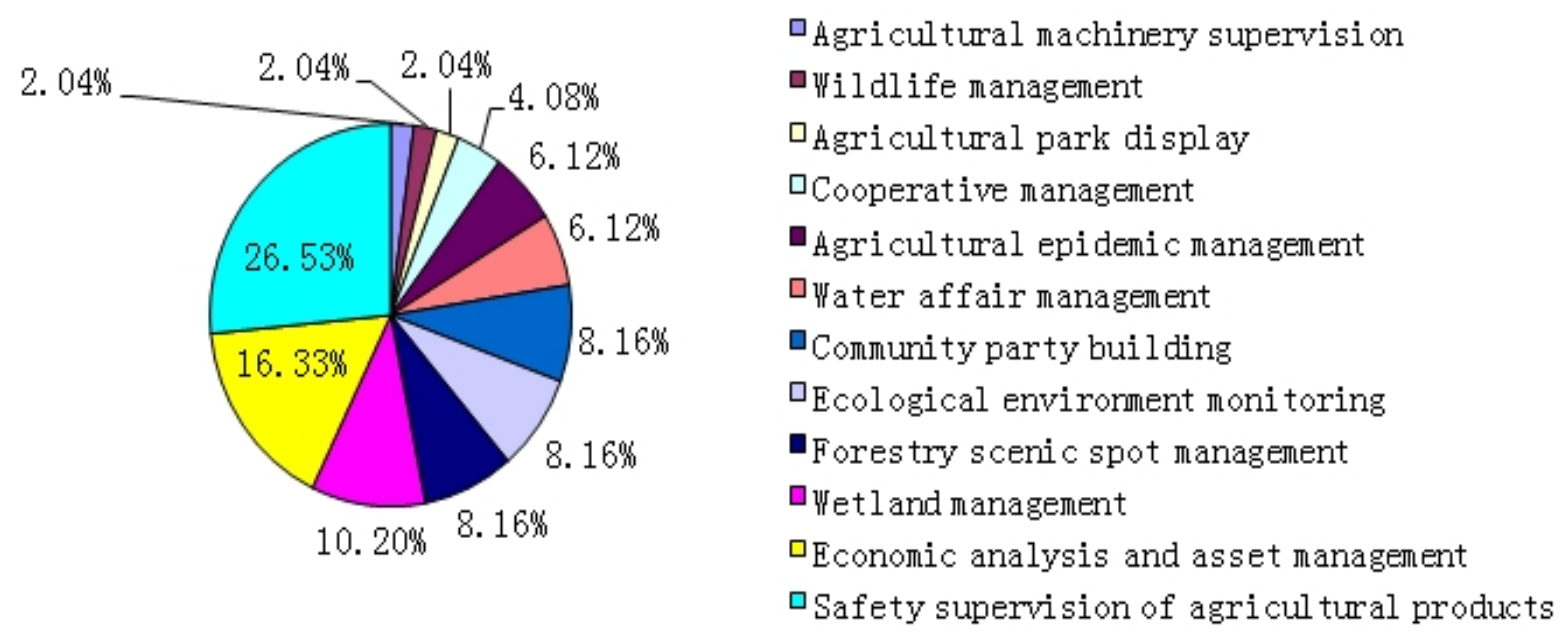

From the Fig.9, agricultural management information system application scope is wide. In it, the ratio of agricultural security policing and asset management for the largest proportion was $26.53 \%$, $16.33 \%$, it reflects that the government recent emphasis on quality and safety management and economic data information collection. Followed by the forestry area management, the ecological environment monitoring, the Community Party construction, $10.2 \%, 8.16 \%, 8.16 \%, 8.16 \%$ respectively. It indicates that the government also pays attention to the natural resources, environment and community organization.

Agricultural public service information system. Classify the information system according to the service method and service content, and statistic the proportion as follows:

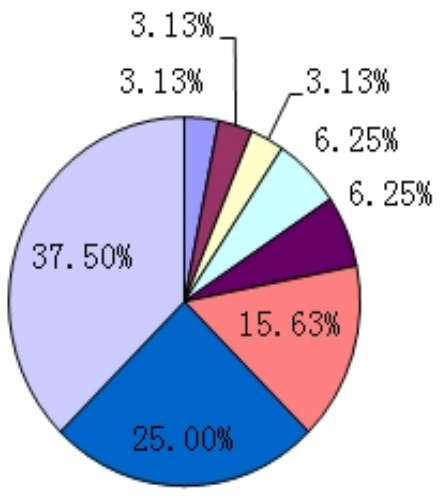

Fig.9 Service way of agricultural public service system
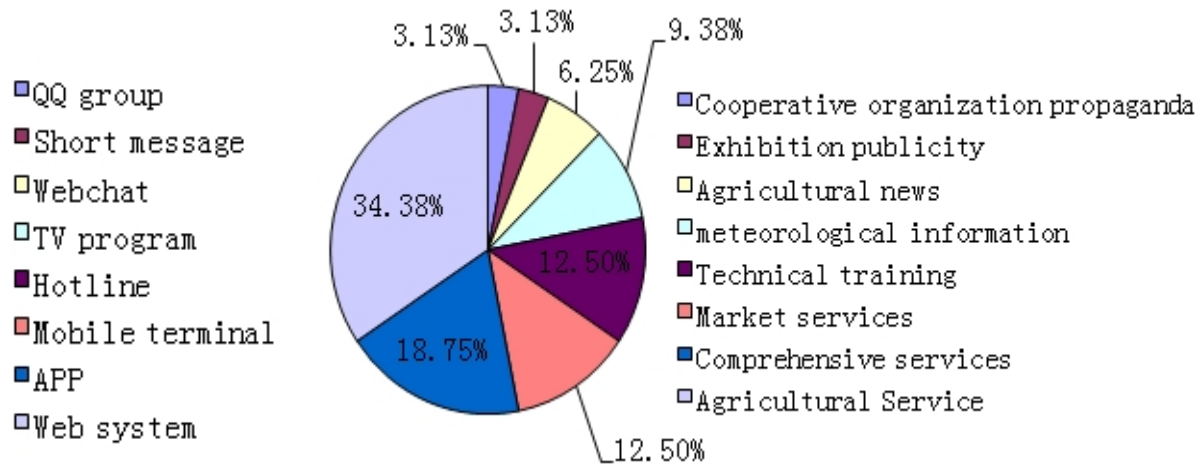

Fig.10 Service content of agricultural public service system 
According to Fig. 10 and Fig. 11, there are 8 types of public service approach, such as website, mobile APP, the mobile terminal, QQ group, TV programs, SMS, hotlines, micro-channel. The application of new emerging media has enriched the service way. The data show that the web service system is still the main channel to agricultural public service. In addition, there is strong development momentum of mobile APP and mobile terminal.

To the service content, the system of providing agricultural technical services is the most, accounted for $34.38 \%$. Followed by comprehensive services, marketing services, science and training services, they are $18.75 \%, 12.5 \%, 12.5 \%$ respectively. In addition, there are systems which service for meteorological, agricultural news, show meeting propaganda and cooperatives recommendation, accounted for $9.38 \%, 6.25 \%, 3.13 \%, 3.13 \%$ respectively.

\section{The development of rural information service system}

Rural information service department. Agricultural information service department has covered each administrative level. At the municipal level, there are Beijing Information Office, Beijing Municipal Rural Work Committee, the Beijing Municipal Bureau of Agriculture, Beijing Academy of Agriculture, and Beijing Agricultural Information Technology Research Center. In the county level, there are county agriculture offices. They are responsible for rural development planning, informationization solutions providing, as well as agricultural technology extension.

\section{Rural information service stations.}

Table 1 Main type statistic of rural information service site

\begin{tabular}{llll}
\hline \multicolumn{1}{c}{ Type } & $\begin{array}{l}\text { "5 one"Rural } \\
\text { information service } \\
\text { station }\end{array}$ & $\begin{array}{l}\text { Village level } \\
\text { service site }\end{array}$ & $\begin{array}{l}\text { Rural party members } \\
\text { remote education } \\
\text { station of }\end{array}$ \\
\hline $\begin{array}{l}\text { Number } \\
\begin{array}{l}\text { Administrative village } \\
\text { coverage rate(\%) }\end{array}\end{array}$ & 130 & 1300 & 3940 \\
\hline
\end{tabular}

There are three main types of agricultural information service site. The remote education station of rural party members is the window of party members education and propaganda. Under the support of the Beijing municipal party committee organization department, it achieves the full coverage in the suburb. Village information service station with touch screen terminal is accounted for $33 \%$, it is also welcomed by farmers. The site of " 5 NO. 1 " is that there is a fixed location, a set of information equipment, an information officer, a set of management system, a long-term mechanism. The coverage rate is $3.3 \%$.

Rural information service team. Beijing has more than 12,000 agricultural information officers. Beijing focuses on service capacity training. The last three years, only the BAAFS conduct the agricultural all-round technician training more than 190 times, 9130 person-time, covering 9 suburban counties.

\section{Characteristics of Beijing agriculture informationization development}

Rural information infrastructure popularity is close to the city. The network and equipment of the mobile communication and broadcast are high.

There is great information demand but with low information skills, information ability is needed to improve, a lot of valuable information services don't use effectively.

Agricultural information system application is widely used. The focus is consistent with the rural development needs. Hot applications are facilities production monitoring, agricultural e-commerce, agricultural product safety regulation, etc

Comprehensive agricultural information service systems are impovmented gradually, the service station construction and staff training is from quantity to quality.

\section{Problems analysis}

The last mile problem of internet broadband and cable network in households still needs to be solved. From the data above, computer usage is not high. There are two reasons for it, one is that 
the parents are worried about their children addicted to the Internet. They don't want to equip with computer. The other is that there are middle-aged and old people man left in the village to engage in the production. They don't know how to use it. Therefore, the problem needs to solve to improve the utilization rate by concept guidance and skill training.

Information skills shortage is the main obstacle to the effective utilization of the achievements. Currently, most farmers still rely on traditional media (TV, newspapers and magazines) to gather information. Only $26 \%$ access to the information by the Internet. Lots of useful resources are staying in information equipment. It doesn't be applied in agricultural production effectively. It restricts the further development of the agricultural informationization to a large extent.

Low-cost and high-quality information service lags behind. Investigation found that, before appeared in economic benefits, information acquisitions costs are the main factors influencing the service receive intend. In addition, for the service quality and validity is uneven, it makes the recognition of the information service in the rural area is uneven, and also cause difficulties in promoting. Provide low-cost and high-quality information services are needed attention.

\section{Countermeasures and suggestions}

Pay attention to the combination of government pushing and market driven, improve the running management mechanism

The government is responsible for the public service by project guidance. The direction of information technology research and scientific achievements is determined and evaluated by the market to motivate the builders' initiative and enthusiasm. Utilize market mechanism to promote the transformation of achievements, and full play the support role to the agricultural industry.

Strengthen the concept guidance and technical training, train modern farmers

Pay attention to the information, production and market ability training, foster a batch of modern new farmers. Promote the skill of obtaining help through various information channels. Let them to experience the benefits by information technology. In agricultural technology, fully considerate the leading industries characteristics, in time in season to carry out the whole chain training of production layout planning, efficient high new technology, marketing, business management to improve the production and management skills.

Use the new technologies and new media to provide high-quality multi-channel precision service

For the new technology application, use big data mining farmers' information needs to provide accurate real-time services. And utilize cloud computing, effectively utilize information resources and reduce the cost of services. For the new media tools application, attaches great importance to the use of mobile phones to provide low cost and accurate information services by QQ, WeChat, micro blog ect.. Promote agricultural information service comprehensive upgrade by various ways.

\section{Acknowledgements}

The research work was supported by the National Sci-Tech Support Plan "Construction and application of provincial rural information service platform in developed area " (NO.2014BAD10B02). Yan Tang is co first author, with the same important contribution to this article. Correspondence to Chang-shou Luo ( luocs@agri.ac.cn ) .

\section{References}

[1] LI Jin, FENG Xian, GUO Mei-rong. Analysis and Countermeasures for the Development of Agricultural Informatization in China. Journal of South China Agricultural University: Social Science Edition,2015, p9-19.

[2] Zhu hong.Influence Factors and System Framework of Agricultural Information Service.Taiyuan Science and Technology,2015,p45-47. 